EJUA-HS Vol. 1 No. 3 (2020)

https://doi.org/10.47372/ejua-hs.2020.3.41

ISSN: 2708-6275

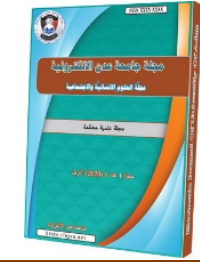

مقالة بحثية

\title{
تدريس نظرية الفوضى لطلبة المرحلة الثانوية من وجهة نظر معلمي الرياضيات
}

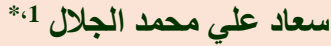

1 التربية والتعليم، عدن، البين

* الباحث الممثل: سعاد علي محمد الجلال، البريد الاككتروني: Suad18224@gmail.com

استلم في: 13 يوليو 2020 / قبل في: 19 أغسط 2020 / نشر في: 07 أكتوبر 2020

(المنحم)

هدفت هذه الدر اسة إلى معرفة أهمية تدريس نظرية الفوضى لطلبة المرحلة الثانوية من وجهة نظر معلمي الرياضيات. واقتصرت الدراسة

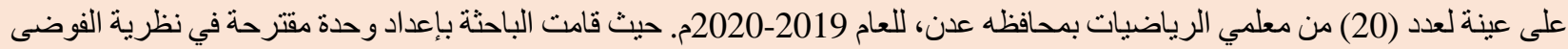

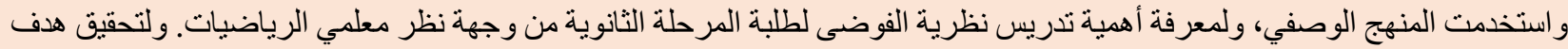
الدر اسة أعدت الباحثة وحدة مقترحة في نظرية الفوضى و استبيان لمعرفة الأهمية ومناسبة هذه الوحدة لطلبة المرحلة الثانوية، و لاختبار دلالة

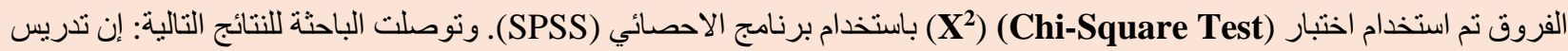

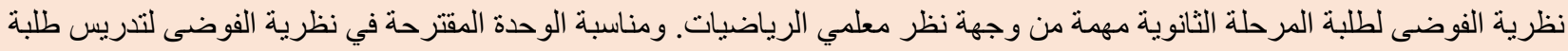
المرحلة الثانوية من حيث: (الأهداف، المحتوى، لمنة التقويم).

وفي ضوء ذلك قدمت الباحثة عدد من التوصيات والمقترحات وأبرزها: الاستفادة من الوحدة المقترحة في نظرية الفوضى في في إدخال

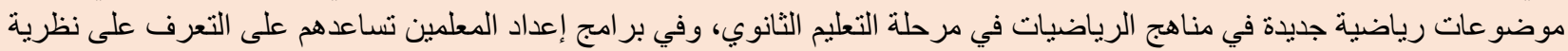

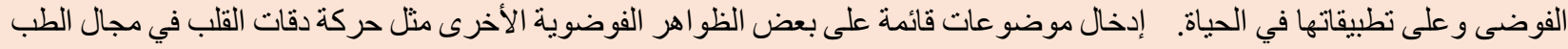
أو حركة كو اكب المجموعة الثمسية في مجال الفضاء و التشفير في مجال الحاسب وذللك في محتوى مناهج الرياضيات بالمرحلة الثانوية.

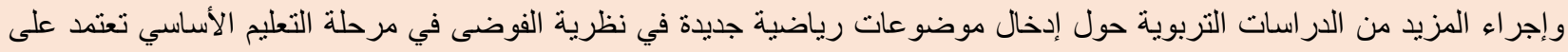

بعض المفاهيم التي تناسب هذه المرحلة.

الكاثمات الرئبسية: نظرية الفوضى، المرحلة الثانوية، معلمي الرياضيات.

: Introduction)

يتميز العصر الحديث بالإنتاج الهائل للمعرفة كماً ونوعاً يصاحبه نغير سريع في التخصصات و الاهنمامات و المصطلحات وحتى وجهات النظر المعرفية، فقد تطورت في الأعو ام الأخيرة طرق تفكير جديدة في حقل الرياضيات مثل نظرية الفوضى (Chaos Theory). هذا الحقل الحقل

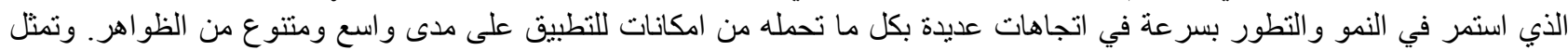

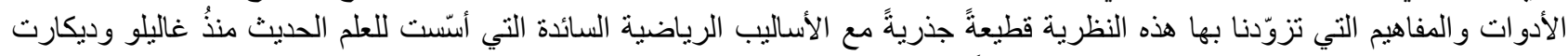

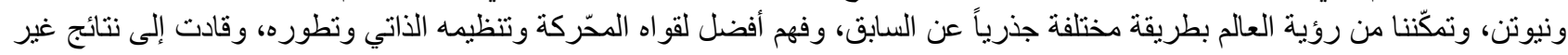

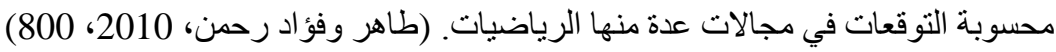

ونظرية الفوضى (Chaos Theory) علم جديد وهو علم ينتمي من الوجهة الرسمية للرياضيات فهو فرع من فروعها. وبينما تتقسم

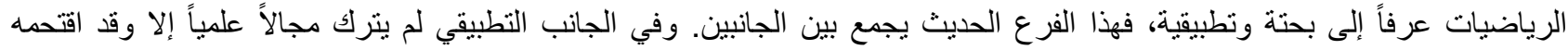

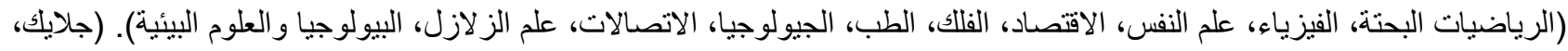

(11،2000

تبدأ نظرية الفوضى (Chaos Theory) من الحدود التي يتوقف عندها العلم التقليدي ويعزز ، وصار مصطئح الفوضى اختصسار الحركة

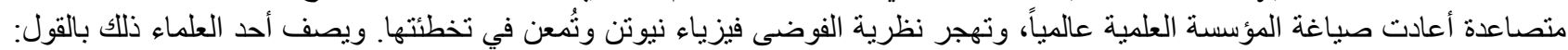

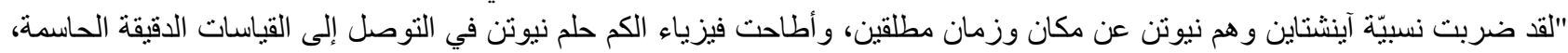

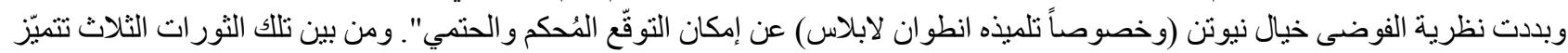

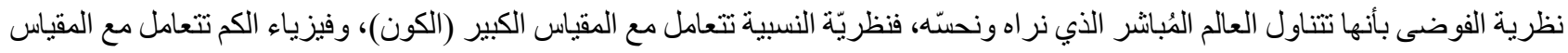


الصغير (الذرّة ودواخلها)، أما نظرية الفوضى فتتأمل في التجارب اليومية والعاديّة للبشر. فالنسبية وفيزياء الكم علوم نظرية، بينما نظرية الفوضى علم عملي. (غليك، 2008، 16-22)

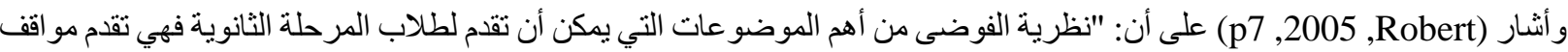

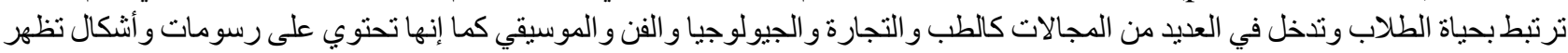

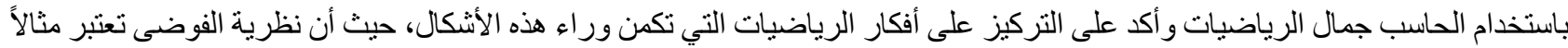
حقبقياً لحل المشكلات و التفكير، لذلك يجب تضمينها في المحتوى الدر اسي".

وبناء على ذللك، فقد جاءت فكرة هذه الدراسة، و التي سوف تسعى الباحثة من خلالها إلى توظيف ومعرفة أهية تدريس نظرية الفوضى لطلبة المرحلة الثنانوية من وجهة نظر معلمي الرياضيات.

\section{مشُكلة الدراسـة (Problem of Study):}

لاحظت الباحثة من خلال عملها كمدرسة لمادة الرياضيات و الاطلاع على كتب المرحلة الثانوية و الجلوس مع بعض معلمي و الموجهين ما

محتوى مادة الرياضيات للمرحلة الثانوية لا يتضمن مشكلات حقبقة من مجالات الحباة المختلقة، مثل مجال الاقتصاد والطقس والبيئة و الجيولوجيا. لا يوجد موضو عات جديدة في هذه المرحلة مما يدعو الحاجة الى تطور حقيقي يتماثىى مع طبيعة العصر عن طريق إدخال موضوعات جديدة تو اكب التطور و التقدم العلمي.

"ركز مؤتمر المشرفين التربويين للرياضيات في مناطق عمل غوث وتثنغيل اللاجئين، و الذي نظم بر عاية منظمة اليونسكو في عمان سنه

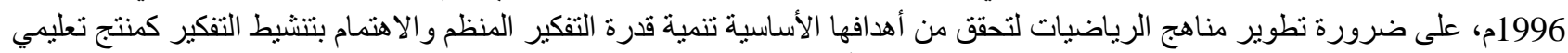

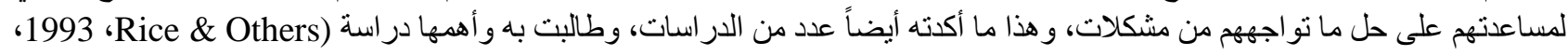

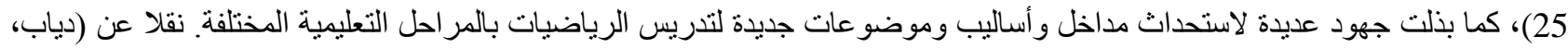

وأنشارت توصيات المؤتمر العلمي السنوي لجمعية تربويات الرياضيات، الى زيادة الاهتمام بموضو عات أكثر تطوير المن حيث فائدنها التطبيقية الحياتية و أعمالها للأنشطة الذهنية مثل نظرية الفوضى. (المؤتمر العلمي السنوي، 2001)

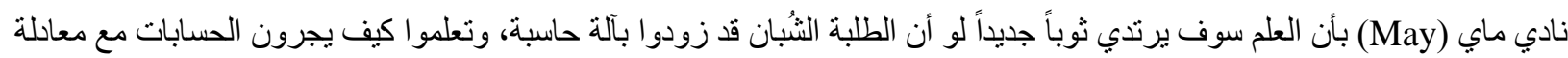

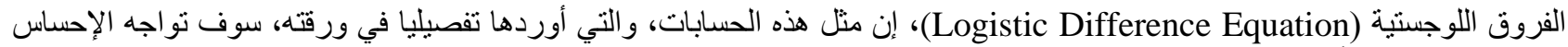

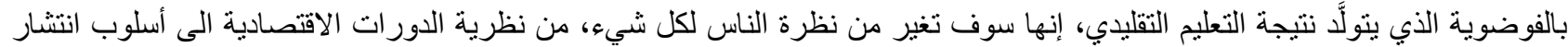

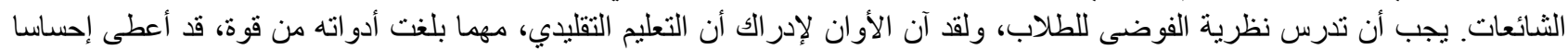

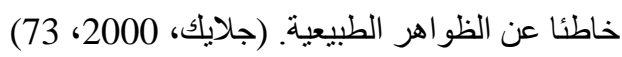

وترى (Elizabeth Kellen، 1998) بأن "هناك حاجة لتعريف الطلبة بتطور العلوم الرياضية، فنظرية الفوضى غنية بالمبادئ التي

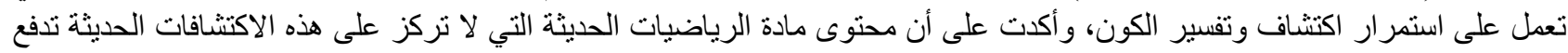

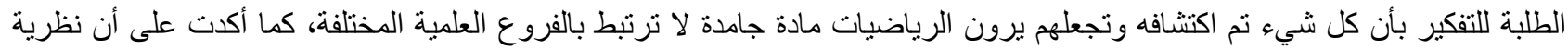

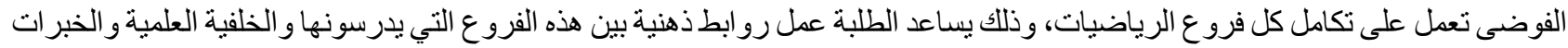

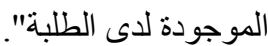

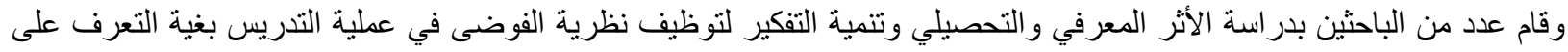

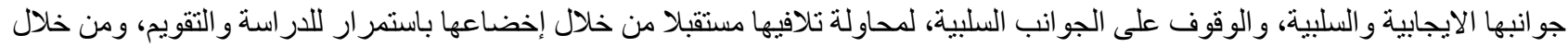
نتائج تلك الدراسات لاحظت الباحثة أن هناك جدوى من نوظيف نظرية الفوضى و أثر ها في تعليم الرياضيات، كدراسة كل من : (Heany)،

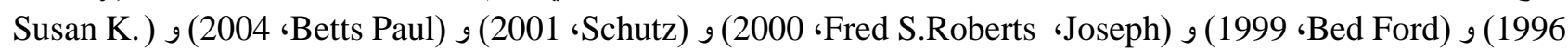

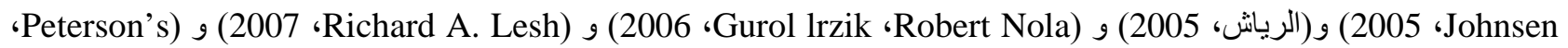
2007)، (أحمد، 2008) و (نمر، 2010)، (الجدري، 2017).

ومن العرض السابق ندرك أهمية ودور نظرية الفوضى في العملية التعليمية، وأن استخدامها في التدريس قد يحقق الكثير من النتائج التعلمية

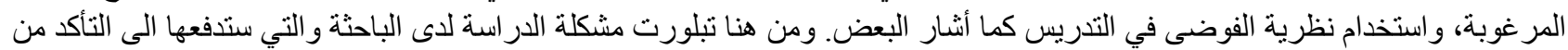


أهمية نظرية الفوضى في مجال التعليم و التعلم ودور ها في تحقيق أهداف تدريس الرياضيات. ولمزيد من الفهم حول مشكلة الدراسة فإن مشكلة هذه الدراسة تتمحور في السؤال الرئيسِ التالي:

ثـ ما أهمية تدريس نظرية الفوضى لطلبة المرحلة الثانوية من وجهة نظر معلمي الرياضيات؟

أهمبــة الار اســة (Significance of Study) تكمن أهمية الدراسة في النقاط التالية:

1) محاولة تطوير محتوى مادة الرياضيات عن طريق إدخال موضو عات جديدة تو اكب التطور والتقدم العلمي.

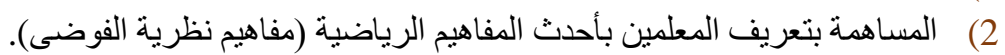

3) فتح المجال أمام بحوث ودر اسات أخرى لاستخدام نظرية الفوضى في صفوف در اسية مختلفة.

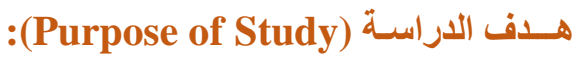
تهــدف الدر اســـة إلـــى:

ثر إعداد وحدة مقترحة في نظرية الفوضى يمكن استخدامه في تطوير المناهج الدر اسية.

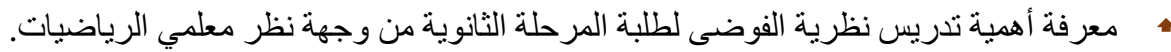

أسئلة: الار استة (Questions of Study)

• ما أهمية تدريس نظرية الفوضى لطلبة المرحلة الثانوية من وجهة نظر معلمي الرياضيات؟

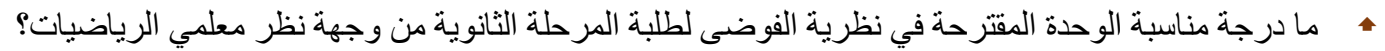

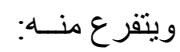

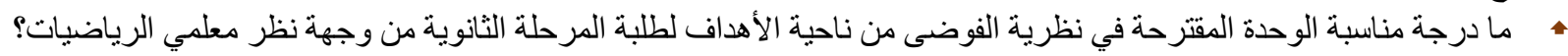

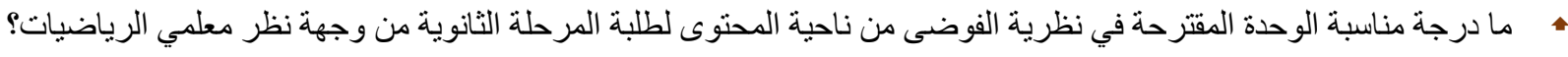
ـ ما درجة مناسبة الوحدة المقترحة في نظرية الفوضى من ناحية اساليب التقويم لطلبة المرحلة الثانوية من وجهة نظر معلمي الرياضيات؟

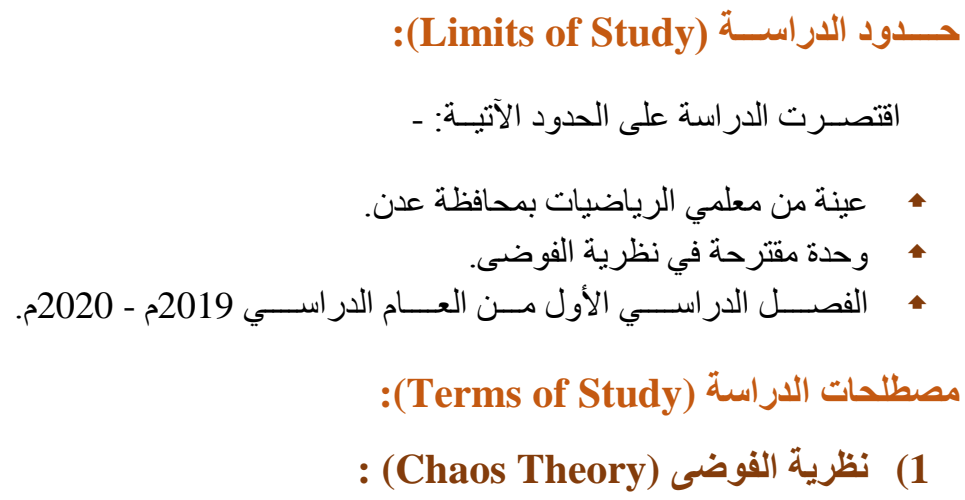

ثـ عرفها (عبيد، 2001، 12) على انها: "مجمو عة من الطرق العددية والرياضية و الهندسية التي تتيح لنا التعامل مع مشكلات غير خطية

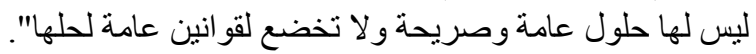

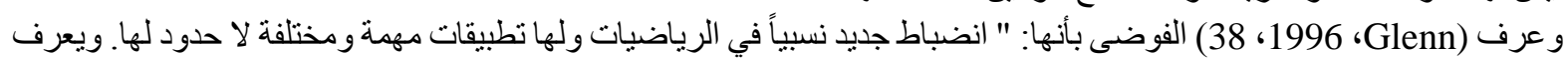

نظرية الفوضى بأنها تصف مدى معين من السلوكيات الغير طبيعية في الأنظمة المتحولة أو المتغيرة".

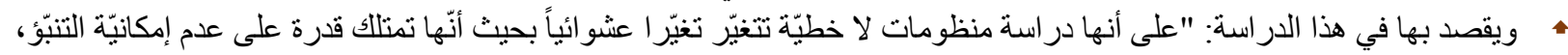

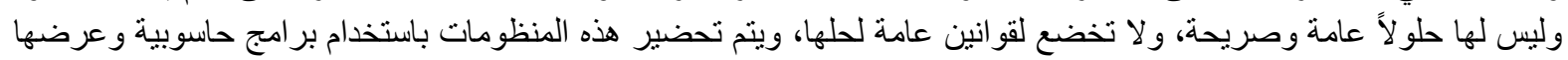
لمعلمي الرياضيات لإبداء أر اءهم حول أهمية تدريس نظرية الفوضى لطولة لطلبة المرحلة الثانوية".

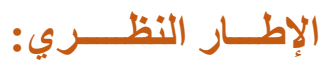

1 1

نظرية الفوضى (Chaos Theory): هي فرعة من فروع الرياضيات الحديثة وتهدف الى ترجمة ما اكتشفه العلماء في الطبيعة من ظو اهر

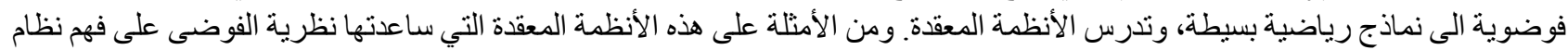
الطقس في الأرض و الفلك و السياسة والاقتصاد أو سلوك الماء المغلي أو أنماط الطيور المهاجرة أو انتشار الغطاء النباتي، الفوضى فئهي في كل مكان، 
من اعتبار ات الطبيعة الحميمة إلى الفن من أي نوع. و على الرغم من أن العديد من الأنظمة المعقدة يبدو أنها تتصرف بطريقة عشو ائية، إلا أن

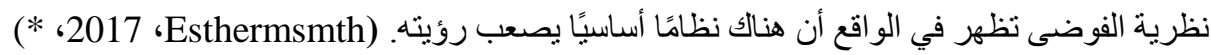

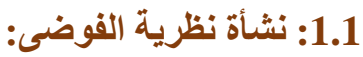

ظهرت كلمة "الفوضى" (Chaos) لأول مرة في العام (700 ق.م) لدى الثناعر الإغريقي هسيود (Hesiod) في قوله: "في البدء كان

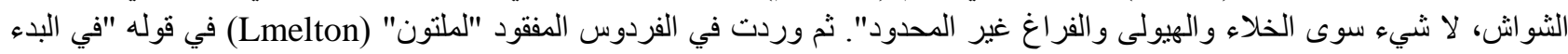

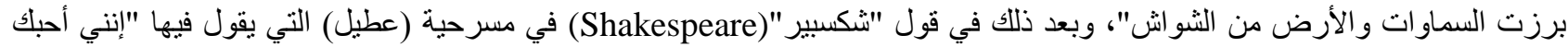

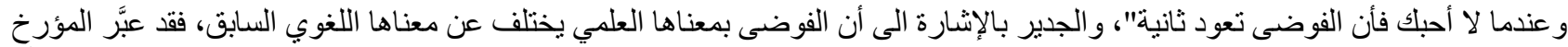

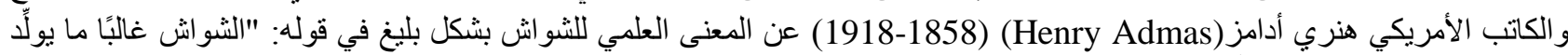
الحياة، بينما النظام Order يولِّد العادة."(عبيد، 2001، 14 (14)

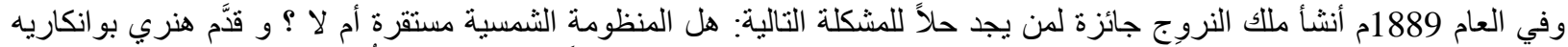

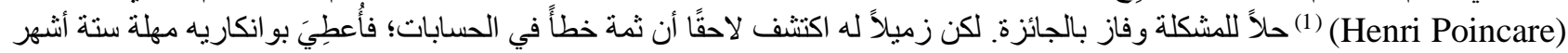

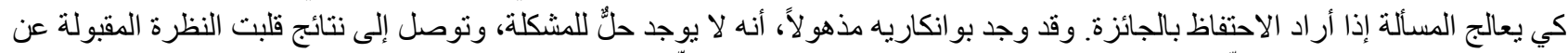

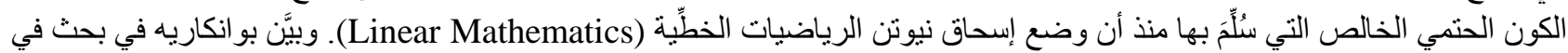

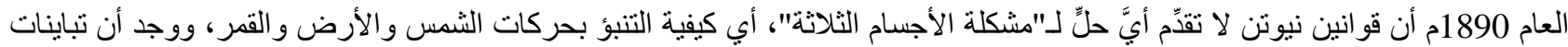

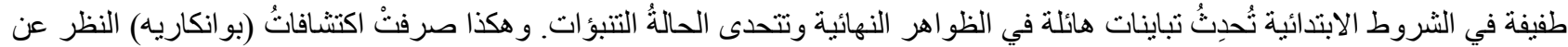

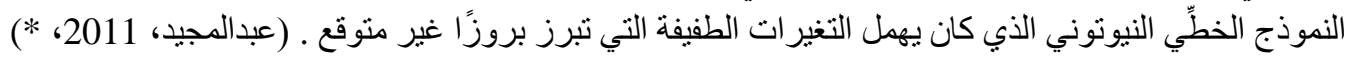

وقد ابتدأت نظرية الفوضى بداية علمية بحتة في مستهل الستينيات الميلادية من القرن الماضي من خلال أعمال المتخصص بالأرصاد

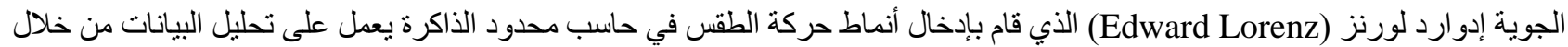

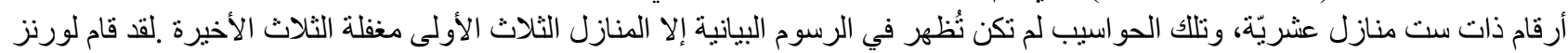

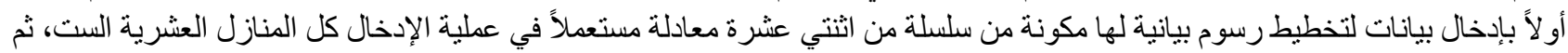

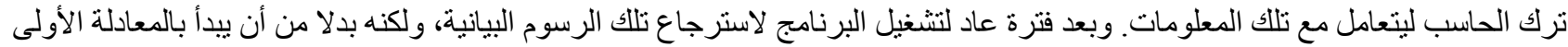

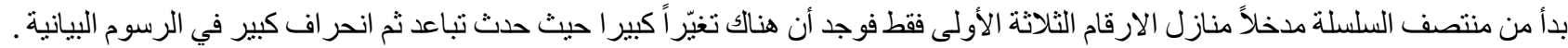

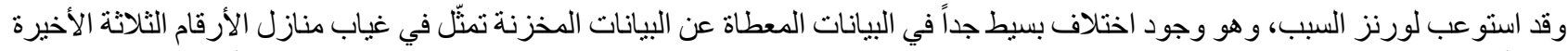

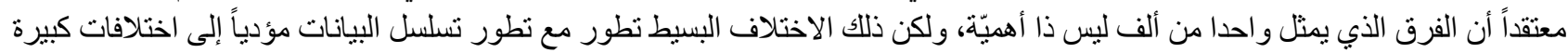

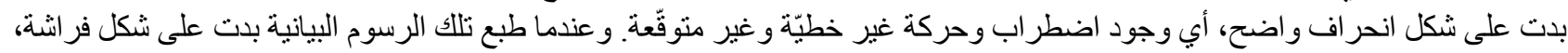

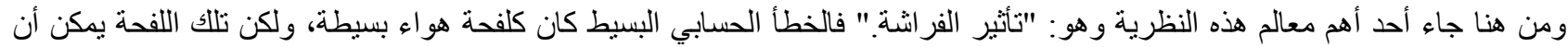

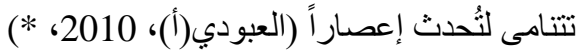

وفي عام 1964م أثبت عالم الرياضيات الروسي إيه إن شاركوفسكي (Iyh iina Sharkwfsky) نظرية لافتنهُ حول الأنماط السلوكية للعديد

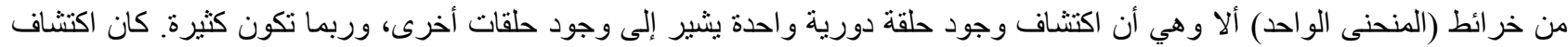

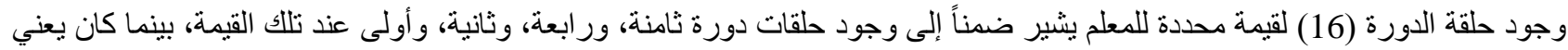

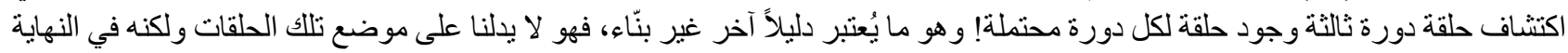

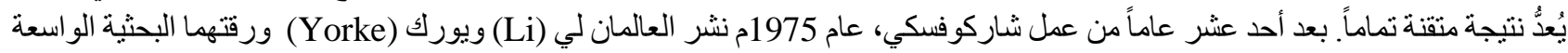
التأثير تحت عنوان رائع : "الدورة الثالثة تستلزم الفوضى". ومن وقتها ظهر مصطلح "الفوضى Chaos" واستقر في الأذهان. (سميث، 2016،

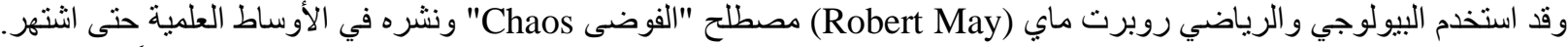

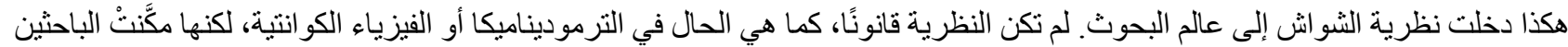

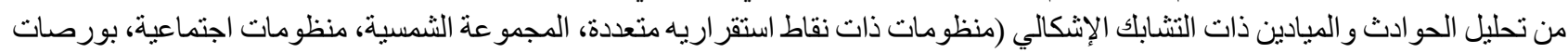

إلـخ). (ابو زيد، 2006، * * ( لعملة واحدة ، يعتبر أول من تنبأ بنظرية الفوضى ووصل الكى أكتشافات قريبةً من لورينز 


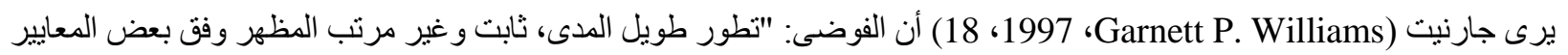
الرياضية الخاصة، ويحدث في نظام لا خطي وحتمي. ويعرف نظرية الفوضى بأنها: المبادئ و العمليات الحسابية الأساسية للفوضى" التئ.

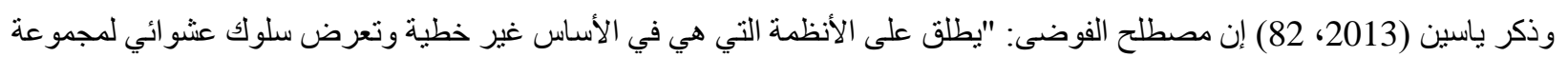

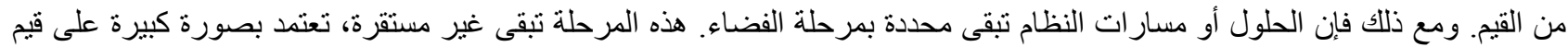

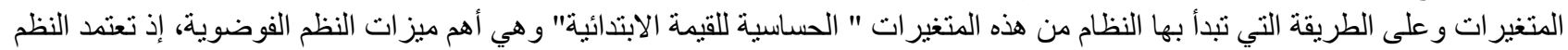

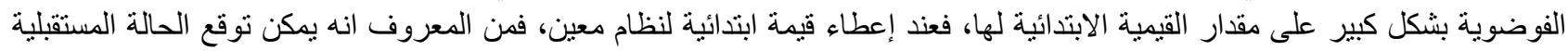

للنظام، إلا أنه في أنظمة الفوضى فير مفار توقع المدى البعيد يستحيل التنبؤ به".

و ورف عبد المجيد (2011) نظرية الفوضى "بأنها دراسة نوعية للسلوكيات غير المنتظمة غير المستقرة في أنظمة حتمية لا خطية وحركية، وقد لوحظ السلوك العشو ائي عندما لم يكن هنالك تغير ا، وقد وصفت حالة النظام التي تتكيف مع تكر ار قيم النظام".

وترى الباحثة أن تعريف نظرية الفوضى هي: مجمو عة من الطرق العددية والرياضية و الهندسية التي تتيح لنا التعامل مع المشكلات غير

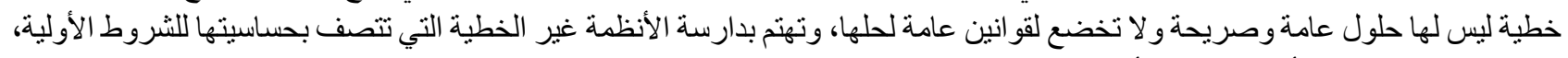

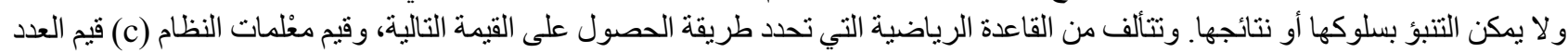
الثابت في القاعدة، والحالة الحالية (القيمة الابتدائية).

3.1

تتميز الظو اهر الفوضوية (الأنظمة الفوضوية) بعدد من الخصائص تميزها عن الأنظمة غير الفوضوية، حلَّدها (Ljupco \& Shinguo،

2010، 10) بالخصائص الأتية:

• الاعتماد على حساسية الثروط الأولية: فالتغير ات الصغيرة في القيم الأولية للنظام ينمو مع مرور الوقت، وتتتج الاختلافات فيستحيل

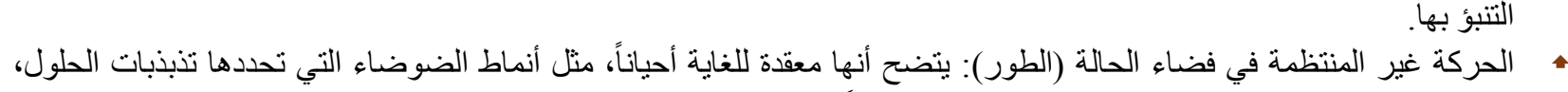

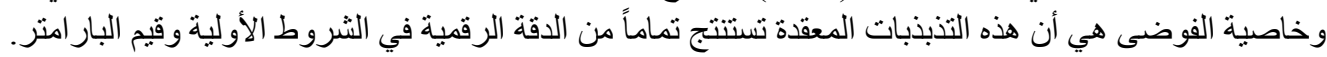

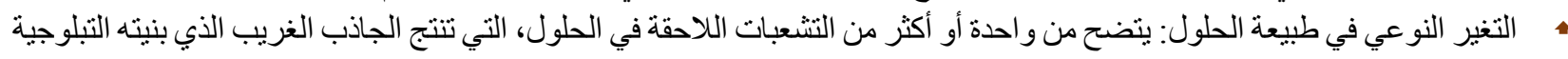
لا تثبه على الإطلاق الحلول الأخرى.

وذكر (سميث، 2016، 29) السمات الثناث الموجودة في النظم الرياضية الفوضوية "النظم الفوضوية تتميز بأنها لا خطية، وحتمية، وغير مستقرة من حيث إنها تظهر حساسية تجاه الثرط المبلئي."

1.4 - المبادئ الرئيسية لنظرية الفوضى:

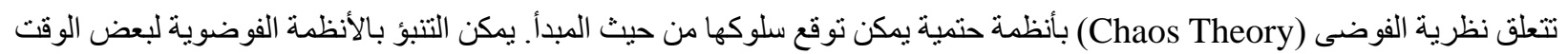

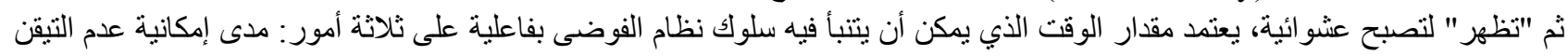

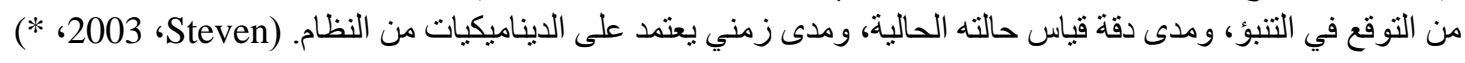
وأبرز زينون (2004، 383) المبادئ الرئيسية لنظرية الفوضى وهي:

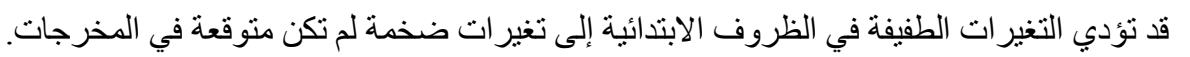

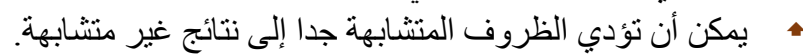

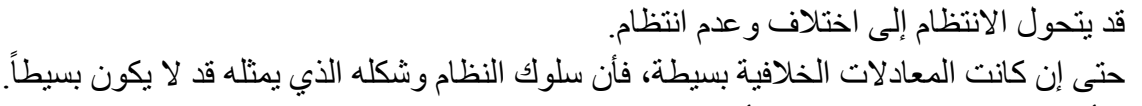
التأثير ات ليست نتائج مباثرة للأسباب.

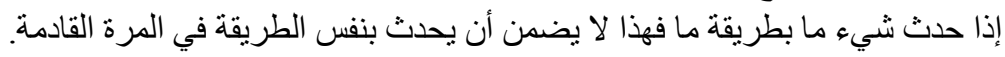
إحلال الأنظمة الحركية محل الأنظمة الحتمية الثابتة.

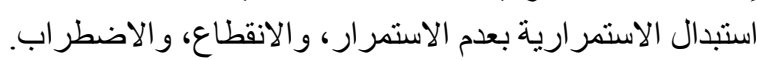

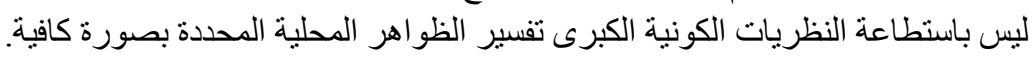
يعد التتبؤ طويل المدى أمراً مستحيلاً. 
ذكر (Rockler، 1991) عدة وظائف لنظرية الفوضى و هي (أحمد، 2008، 33):

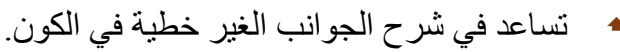

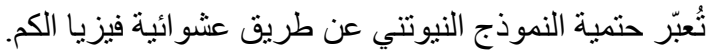

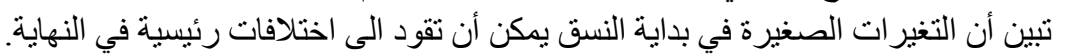

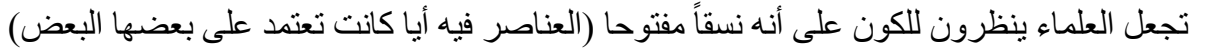

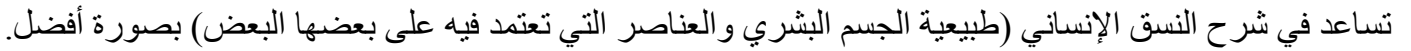

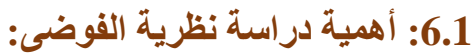

يذكر علي (2000) المجال الأصلي الذي يتناوله هذا العلم (نظرية الفوضى) فهو يبحث ببساطة في النظم الديناميكية، وهى النظم التي تتغير

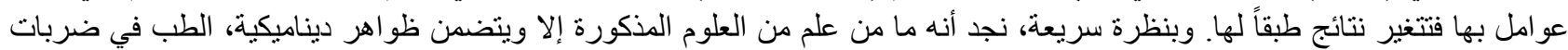

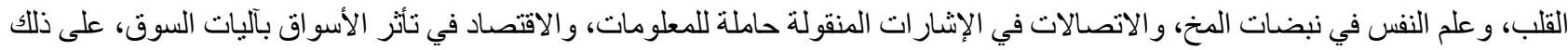

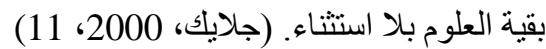

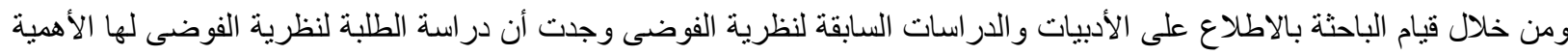
و أهمها ما أثنار إليه الأدب التربوي و التي منها ما ذكر في: (أحمد، 2008، 35-36) و (الجدري، 2017، 35-36) و و(عبيد، 2001، 14) و

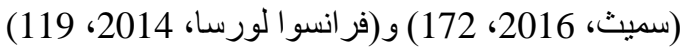

1. تساعد الطلبة على الوصول في تنبؤ قريب الددى لكثير من الظو اهر الكونية وهذا من خلال فرع من فروع الرئ الرياضيات.

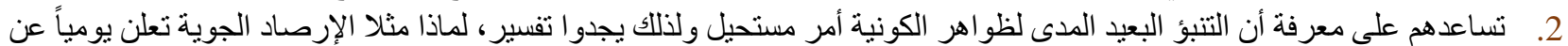

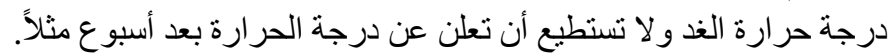

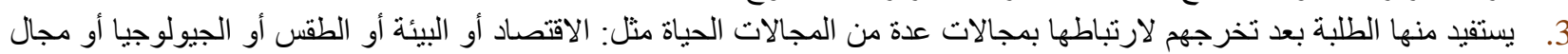

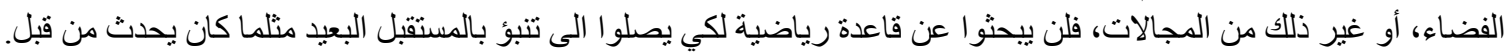

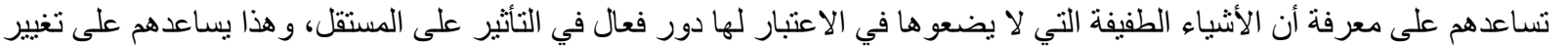

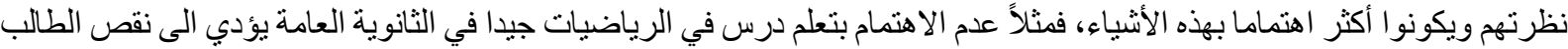

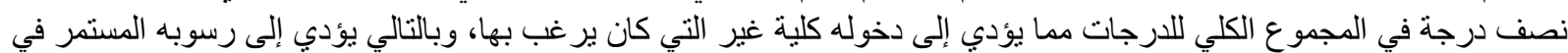

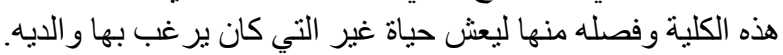

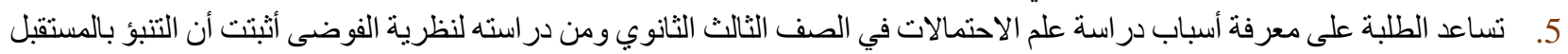

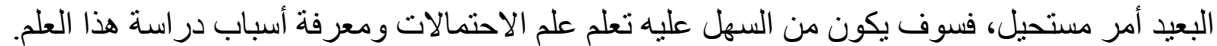
6. تساعدهم على معرفة أن قو انين نيونن التي تدرس في الفيزياء وميكانيكا الصف الثالث الثيات الثانوي، لا تتعامل مع كل المشكلات فهي تتعامل

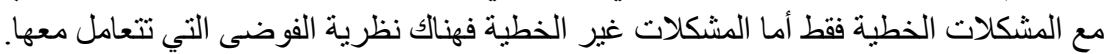

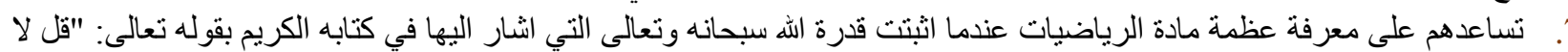

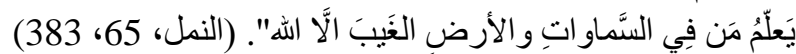

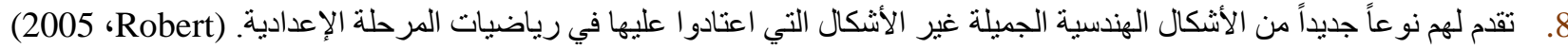

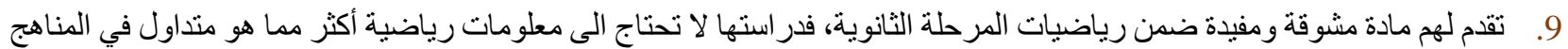

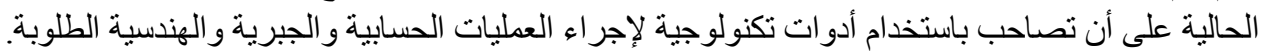

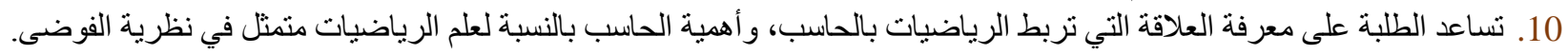

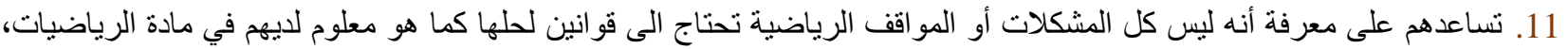

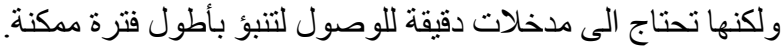

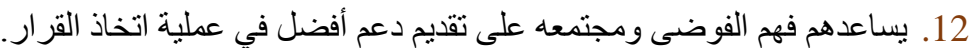

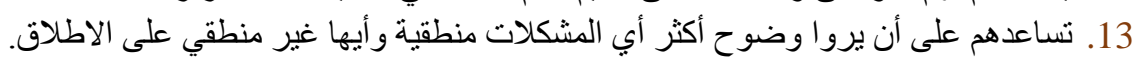

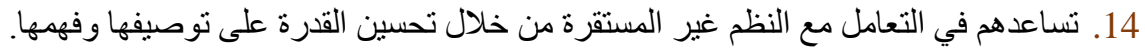

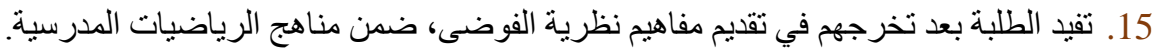
16. تنرح للطلبة الجوانب غير الخطية في الظو اهر الطبيعية.

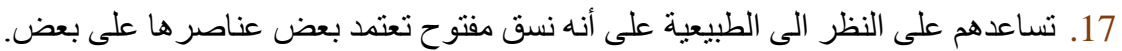

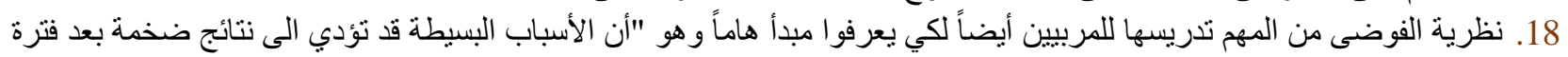

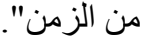


و هذا ما دفع الباحثة الى معرفة أهمية تدريس نظرية الفوضى ودرجة مناسبتها لطلبة المرحلة الثانوية من وجهة نظر معلمي الرياضيات، باعتبار أن مادة الرياضيات أوثق العلوم ارتباطاً بنظرية الفوضى.

\section{دراسات سابقة ( Previous Studies )}

قام الجدري (اليمن، 2017) بدر اسة هدفت الى بناء برنامج مقترح في نظرية الفوضى وقياس فاعليته في تتمية القدرة على حل المشكلات

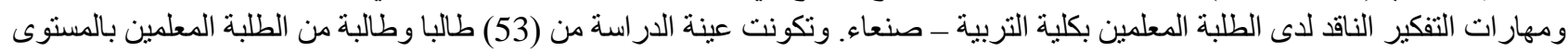

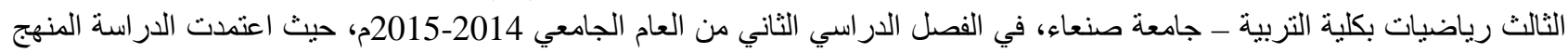

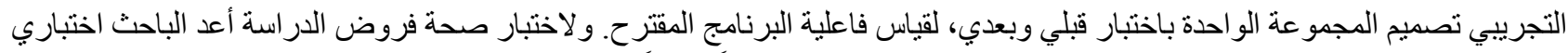

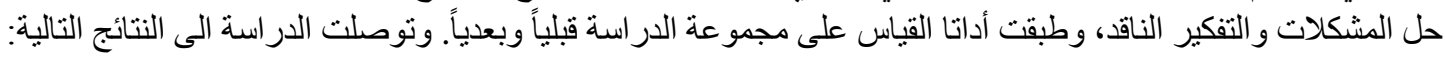

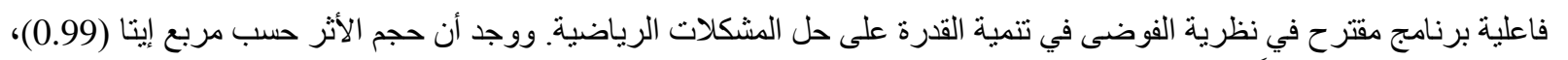

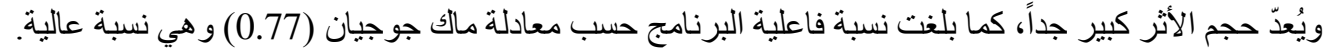

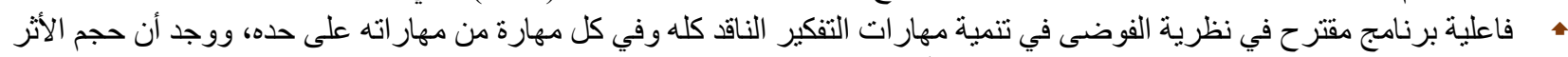

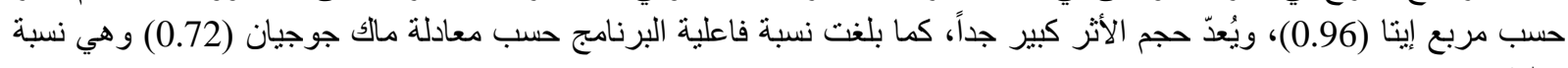
عالية.

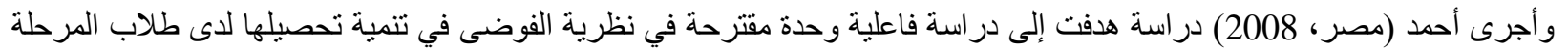

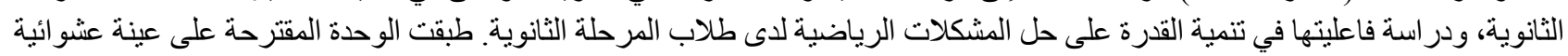

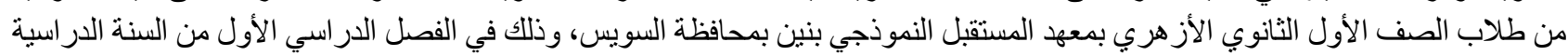

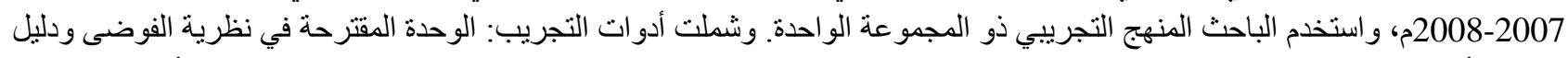

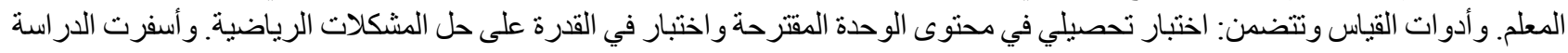

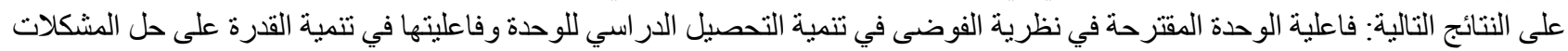

و أما دراسة London) Richard A. Lesh، وفئ 2007) فقد هدفت إلى تطوير محتوى منهج الرياضيات في بر امج إعداد المعلمين من خلال

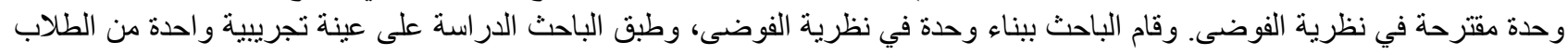

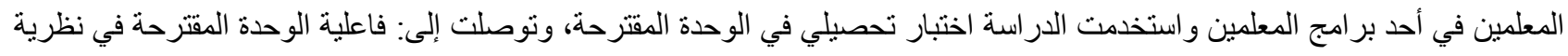
الفوضى في تطوير محتوى منهج الرياضيات في بر امج إعداد المعلمين.

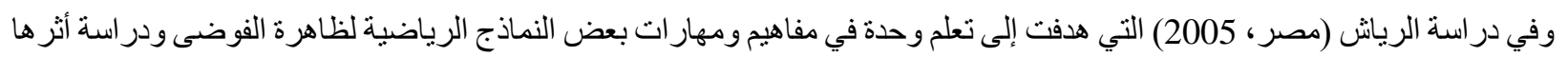

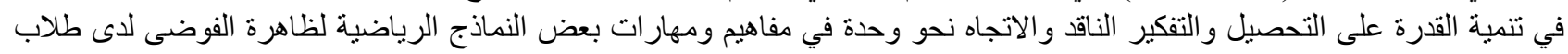

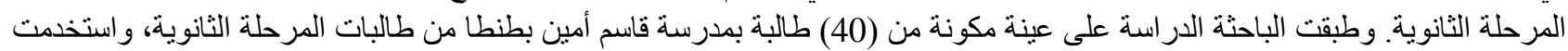

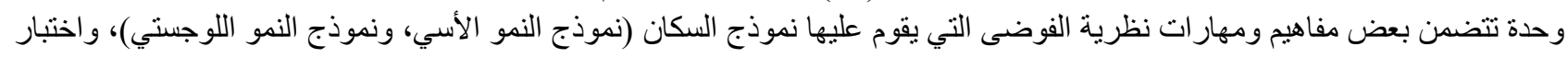

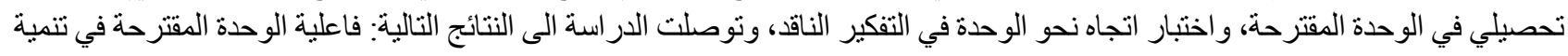
التحصيل في الوحدة المقترحة و القدرة على التفكير الناقد لاى طلبة المرحلة الثانوية. وفاعلينها في تتمية اتجاه الطلبة نحو الوحدة الوحدة.

تعقيب على الار اسات السابقة:

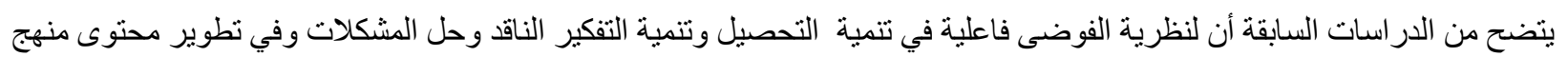

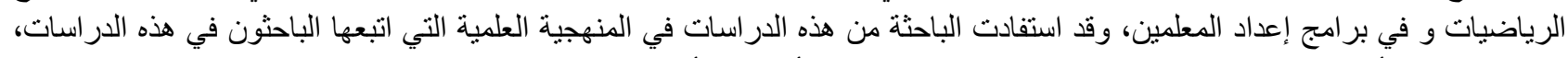

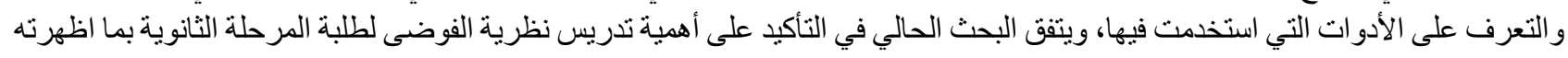

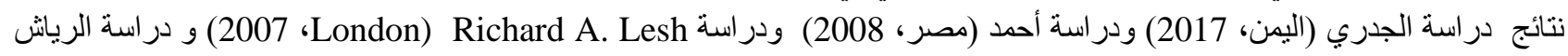
(مصر، 2005)، ويُعد هذا البحث استكمالا للار اسات السابقة وإضافة إلئه إليها.

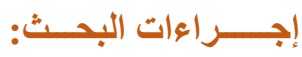

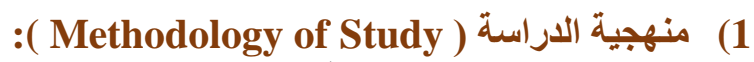
اتبعت الدر اسنة المنهج الوصفي نظراً لملائمته لأغر اض هذه الدراسة.

مجتمع الدراسة وعينته ( Population and Sample of Study) : 
تألف مجتمع الدراسة من جميع معلمي الرياضيات في محافظة عدن للعام الدراسي 2019 - 2020م واختارت الباحثة عينة عشو ائية من هذا المجتمع بلغ عدد أفر اد العينة (20) معلم ومعلمة، و وليه شكلت عينه الدر اسنة.

مستئزمات الدراسة (Preparation of Study Requirement)

الوحدة المقترحة في نظرية الفوضى.

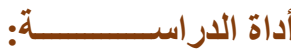

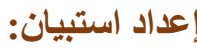

مّر إعداد الاستبيان بالخطو ات الآتية:

1) هذف الاستيان: تحديد درجة مناسبة الوحدة المقترحة في نظرية الفوضى وأهمية تدريسها لطلبة المرحلة الثانوية.

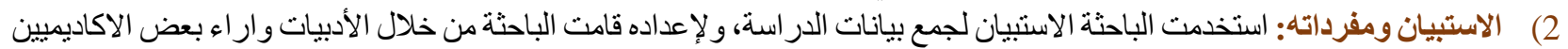

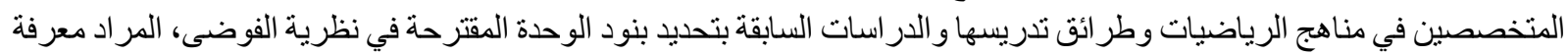

أراء معلمي الرياضيات فيها.

3) صدق الاستبيان: بعد إعداد الاستيبان، عُرضنَ على المحكمين في أدوات الدراسة لإبداء آرائهم فيه من حيث: الصياغة، ومناسبتها وما

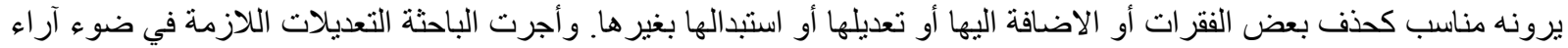

المحكمين، وكذللك تم تجريب الاستبانة على مجمو عة من المعلمين.

إجراءات تطبيق الدراسة:

بعد أن تم إعداد الوحدة المقترحة في نظرية الفوضى وإعداد أداة الدراسة من قبل الباحثة في صورتهما النهائية، أصبح جاهز ألتطبيقه على الإلى

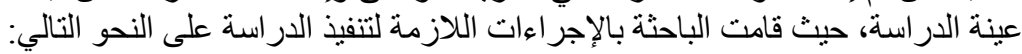

1) أخذ المو افقات من الجهات الرسمية لتطبيق الدر اسة.

2) توزيع الأداة على عينة الدراسة.

3) تابعت الباحثة توزيع واستعادة أداة الدر استة.

4) ) جمع الاستبانات وتصنيفها ونرقيمها.

5) استغرقت تطبيق أداة الدر اسة وجمعها شهرين تقريبا وتم ذللك خلال العام الدراسي 2019-2020م

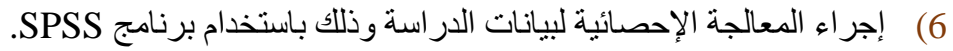

7) عرض النتائج وتفسير ها ومناقشتها وتقديم التوصيات و المقترحات.

الأساليب الإحصائية ( Statistical Methods )

استخدمت الباحثة الأساليب الإحصائية باستخدام برنامج (SPSS) بواسطة اختبار مربع كاي (Chi-Square Test)(

$$
\begin{aligned}
& \text { نتائج الدراسة ومناقتُشتها وتقفيرها: } \\
& \text { الإجابة على أسئلة الار اسية: }
\end{aligned}
$$

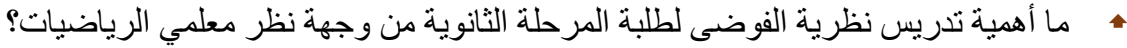

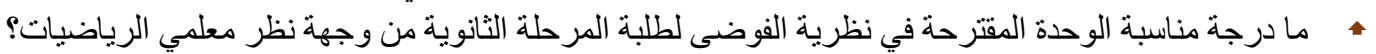

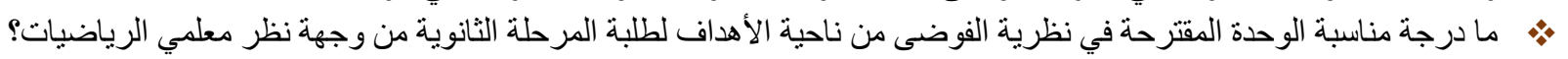

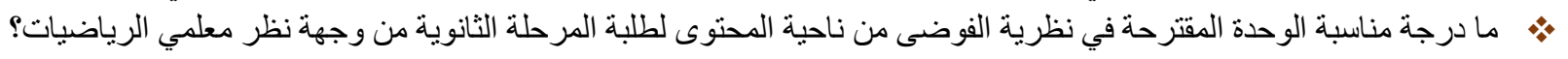

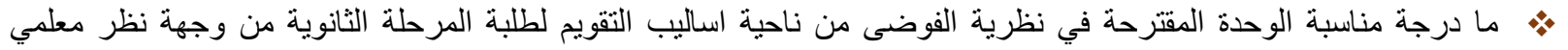

الرياضيات؟

وقد تمت الإجابة عن هذه الأسئلة من خلال بناء الأداة وإخر اجها في صورتها النهائية حيث اشتملت محورين هي: المحور الأول: أهمية تدريس نظرية الفوضى لطلبة المرحلة الثانوية من وجهة نظر معلمي الرياضيات، وأنتنمل على (8) عبار ات. 
المحور الثاني: درجة مناسبة الوحدة المقترحة في نظرية الفوضى لطلبة المرحلة الثانوية من وجهة نظر معلمي الرياضيات، وتمثلت في ثلاثة

البعد الأول: درجة مناسبة الوحدة المقترحة في نظرية الفوضى من ناحية الأهداف لطلبة المرحلة الثانوية من وجهة نظر معلمي الرياضيات، و أشنتمل على (5) عبار ات.

البعد الثاني: درجة مناسبة الوحدة المقترحة في نظرية الفوضى من ناحية المحتوى لطلبة المرحلة الثانوية من وجهة نظر معلمي الرياضيات، وأشنمل على (5) عبار ات.

البعد الثالث: درجة مناسبة الوحدة المقترحة في نظرية الفوضى من ناحية اساليب التقويم لطلبة المرحلة الثانوية من وجهة نظر معلمي الرياضيات، وأشنمل على (4) عبار ات.

وقد بلغ عدد العبار ات جميعاً (22) عبارة واستخدم مقياس ثنائي للاستجابة على الفقرات حيث تم الحكم على الأهمية ومناسبة الوحدة المقترحة

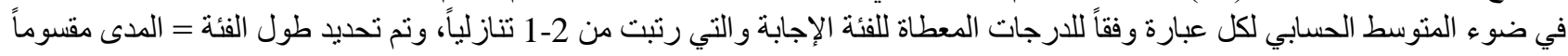
على عدد الفئات وحدد المدى بالمعادلة:

المدى = أكبر قيمة للفئات الإجابة ـ أصغر قيمة للفئات الإجابة = 2-1 = 1، وتحديد درجة مناسبة تدريس نظرية الفوضى لطلبة المرحلة الثانوية من وجهة نظر معلمي الرياضيات باستخدام المعادلة: (طول الفئة) = قسمة المدى على عدد الفئات= 1/2 = 0.5.

جدول(1): درجات وحدود فئات معيار الأهمية

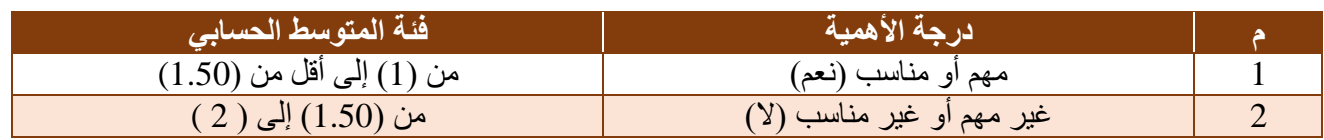

إجابة السؤال الأول:

• ما أهمية تدريس نظرية الفوضى لطلبة المرحلة الثانوية من وجهة نظر معلمي الرياضيات؟

ولإجابة عن هذا السؤال تم استخر اج المتوسطات و الانحر اف المعياري لإجابات عينة الدر اسة حول أهمية تدريس نظرية الفوضى لطلبة المرحلة

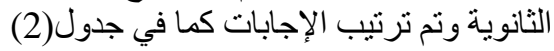

جدول(2): أهمية تدريس نظرية الفوضى لطلبة المرحلة الثانوية

\begin{tabular}{|c|c|c|c|c|c|}
\hline الأهمية & الإحصائية & $\begin{array}{l}\text { Chi- } \\
\text { Square }\end{array}$ & 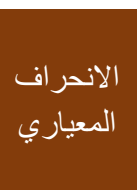 & 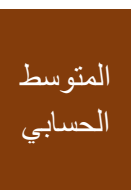 & العبارة \\
\hline مهم & $\begin{array}{c}0.025 \\
\text { دالة }\end{array}$ & 5.000 & 0.44426 & 1.2500 & 1. هل مو اضيع دروس نظرية الفوضى مهمة لتدريسها لطلبة \\
\hline 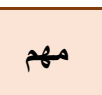 & $\begin{array}{c}0.007 \\
\text { دالة }\end{array}$ & 7.200 & 0.41039 & 1.2000 & 2. هل مواضيع نظرية الفوضى شيقة وتخدم أهداف تدريس \\
\hline 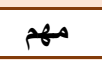 & 0.025 & 5.000 & 0.44426 & 1.2500 & 3. هل مو اضيع نظرية الفوضى مناسبة لطلبة المرحلة الثانوية. \\
\hline 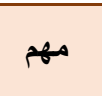 & $\begin{array}{c}0.002 \\
\text { دالة }\end{array}$ & 9.800 & 0.36635 & 1.1500 & 4. هل تساعد الطالب على تنمية مهار ات التفكير الناقد لديه. \\
\hline 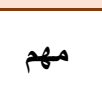 & $\begin{array}{c}0.007 \\
\text { دالة }\end{array}$ & 7.200 & 0.41039 & 1.2000 & 5. هل المو اضيع جديدة على الطلبة. \\
\hline مهم & $\begin{array}{c}0.002 \\
\text { دالة }\end{array}$ & 9.800 & 0.36635 & 1.1500 & 6. هل تربط مو اضيع نظرية الفوضى بين الحاسب و علم \\
\hline 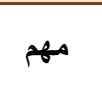 & $\begin{array}{c}0.007 \\
\text { دالة }\end{array}$ & 7.200 & 0.41039 & 1.2000 & 7. هل تساعد الطلبة على خفض مستوى القلق عندهم من \\
\hline 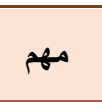 & $\begin{array}{c}0.002 \\
\text { دالة }\end{array}$ & 9.800 & 0.36635 & 1.1500 & 8. هل توفر للطالب أشكال بيانية جديدة غير معتاد عليها في \\
\hline مهم & & & & 1.19375 & 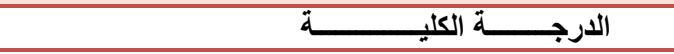 \\
\hline
\end{tabular}


ويتضح من جدول(2) بأن المتوسط الحسابي لأهمية تدريس نظرية الفوضى لطلبة المرحلة الثانوية تراوحت بين (1.15- 1.25) حيث كانت إجابة أفر اد العينة على جميع عبار ات هذا المحور بدرجة مهمة، و عليه فإن تدريس نظرية الفوضى لطلبة المرحلة الثانوية مهمة من وجهة نظر الثران معلمي الرياضيات. إجابة السؤال الثشاني:

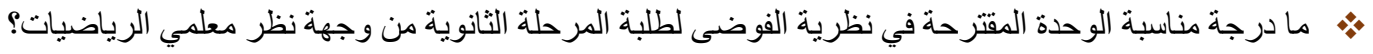

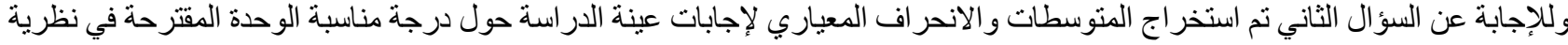

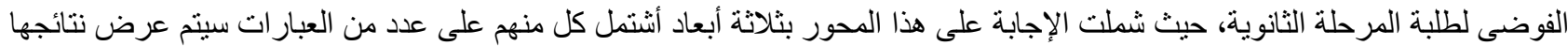

أولاً: درجة مناسبة الوحدة المقترحة في نظرية الفوضى من ناحية الأهداف لطلبة المرحلة الثانوية من وجهة نظر معلمي الرياضيات، ورتبت إجابات عينة الدراسة عن درجة مناسبة عبار ات هذا البعد كما في جدول(3) ناسة):

\section{جدول(3): درجة مناسبة الوحدة المقترحة في نظرية الفوضى من ناحية الأهداف لطلبة المرحلة الثانوية}

\begin{tabular}{|c|c|c|c|c|c|}
\hline درجة الأهمية & 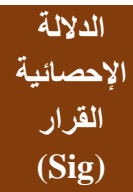 & Chi-Square & الاعراف المعياري & المتوسط & 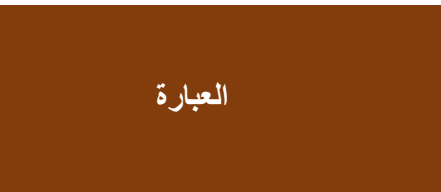 \\
\hline مناسب & 0.000 & 16.200 & 0.22361 & 1.0500 & 1. مصاغة بصورة واضحة. \\
\hline 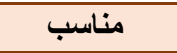 & 0.000 & 12.800 & 0.30779 & 1.1000 & 2. ت تميزت بالتنوع. \\
\hline 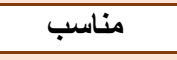 & 0.000 & 16.200 & 0.22361 & 1.0500 & 3. ارتبطت بأهداف تعليم الرياضيات. \\
\hline 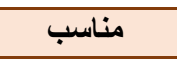 & 0.000 & 16.200 & 0.22361 & 1.0500 & 4. ممكنة التحقق. \\
\hline 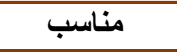 & 0.000 & 16.200 & 0.22361 & 1.0500 & 5. قابلة القياس. \\
\hline مناسب & & & & 1.0600 & الارجـــة الكليــــــة \\
\hline
\end{tabular}

ويتضح من جدول(3) بأن المتوسط الحسابي لدرجة مناسبة الوحدة المقترحة في نظرية الفوضى من ناحية الأهداف لطلبة المرحلة الثانوية الثانية

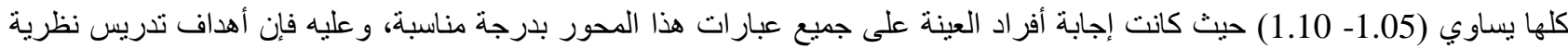
الفوضى لطلبة المرحلة الثانوية مناسبة من وجهة نظر معلمي الرياضيات.

ثُانياً: درجة مناسبة الوحدة المقترحة في نظرية الفوضى من ناحية المحتوى لطلبة المرحلة الثانوية من وجهة نظر معلمي الرياضيات، ورتبت إجابات عينة الدراسة عن درجة مناسبة عبار ات هذا البنة البعد كما في جدول(4):

جدول(4): درجة مناسبة الوحدة المقترحة في نظرية الفوضى من ناحية المحتوى لطلبة المرحلة الثانوية

\begin{tabular}{|c|c|c|c|c|c|}
\hline الأهمية & الإحصائية & $\begin{array}{l}\text { Chi- } \\
\text { Square }\end{array}$ & الاتحراف المعياري & المتوسط & 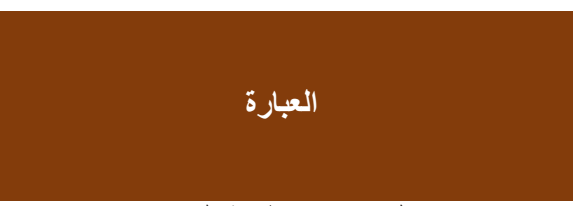 \\
\hline 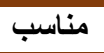 & 0.000 & 12.800 & 0.30779 & 1.1000 & 1. ركزت على مفاهيم نظرية الفوضى. \\
\hline 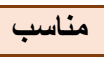 & 0.007 & 7.200 & 0.41039 & 1.2000 & 2. مناسب للفئة العمرية (للطلبة المرحلة الثانوية). \\
\hline 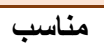 & 0.000 & 16.200 & 0.22361 & 1.0500 & 3. منظم منطقياً. \\
\hline 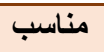 & 0.007 & 7.200 & 0.41039 & 1.2000 & 4. خطوات الدروس مرتبة. \\
\hline 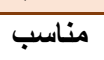 & 0.000 & 16.200 & 0.22361 & 1.0500 & 5. الصياغة اللغوية سليمة. \\
\hline 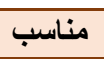 & & & & 1.1200 & الدارجــــــة الكلي \\
\hline
\end{tabular}

ويتضح من جدول(4) بأن المتوسط الحسابي لارجة مناسبة الوحدة المقترحة في نظرية الفوضى من ناحية المحتوى لطلبة المرحلة الثانوية

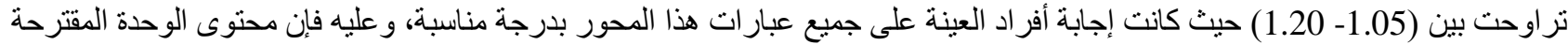
في نظرية الفوضى لطلبة المرحلة الثانوية مناسبة من وجهة نظر معلمي الرياضيات. 
ثأثاً: درجة مناسبة الوحدة المقترحة في نظرية الفوضى من ناحية اساليب التقويم لطلبة المرحلة الثانوية من وجهة نظر معلمي الرياضيات، ورتبت إجابات عينة الدراسة عن درجة مناسبة عبار ات هذا البعد كما في جدول(5):

\section{جدول(5): درجة مناسبة الوحدة المقترحة في نظرية الفوضى من ناحية اساليب التقويم لطلبة المرحلة الثانوية}

\begin{tabular}{|c|c|c|c|c|c|}
\hline الأهمية & الإحصائية & $\begin{array}{l}\text { Chi- } \\
\text { Square }\end{array}$ & الالمعرافي & المتوسط & 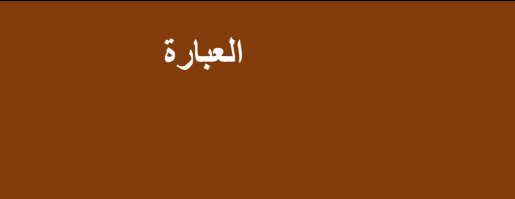 \\
\hline 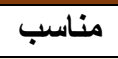 & 0.007 & 7.200 & 0.41039 & 1.2000 & 1. ت تتسم بالتتوع. \\
\hline 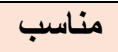 & 0.000 & 12.800 & 0.30779 & 1.1000 & 2. مناسبة لقياس أهداف البرنامج. \\
\hline مناسب & 0.000 & 12.800 & 0.30779 & 1.1000 & 3. متدرجة من حيث السهولة و الصعوبة. \\
\hline 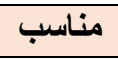 & 0.007 & 7.200 & 0.41039 & 1.2000 & 4. تراعي الفروق الفردية بين الطلبة. \\
\hline 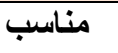 & & & & 1.1500 & الارجـــــــة الكليـ \\
\hline
\end{tabular}

ويتضح من جدول(5) بأن المتوسط الحسابي لدرجة مناسبة الوحدة المقترحة في نظرية الفوضى من ناحية اسلاليب التقويم لطلبة المرحلة

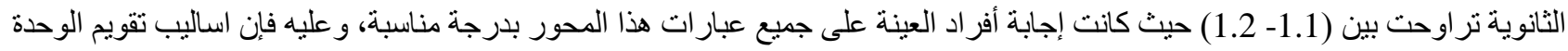

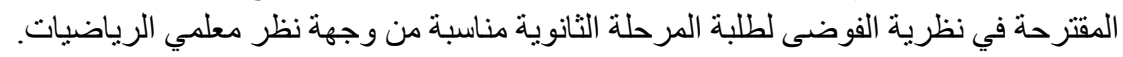

ومن إجابات الثلاثة الأبعاد السابقة تكون الإجابة على السؤال الثاني أن الوحدة المقترحة في نظرية الفوضى مناسبة لتدريسها لطلبة المرحلة الثانوية.

وتتفق نتائج هذه الدر اسة بأهميتها مع ما قدمته نتائج دراسة الجدري (اليمن، 2017) ودر اسة أحمد (مصر، 2008) ودراسة مichard واس 2005)، London) A. Lesh توصيات ومقترحات: في ضوء ما أسفرت عنه نتائج الدراسة توصي الباحثة بما يلي: ثـ إدخال موضوعات رياضية جديدة في مناهج الرياضيات في مرحلة النعليم الثانوي، واستخدامها في تتمية قدرة الطلبة على التفكير الناقد وحل المشكلات الرياضية. •. إدخال موضو عات جديدة في نظرية الفوضى في بر امجية إعداد المعلمين تساعدهم على التعرف على نظرية الفوضى و على تطبيقاتها في

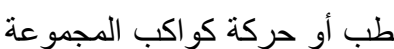

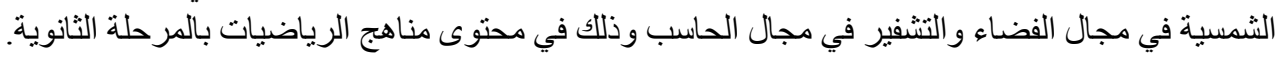

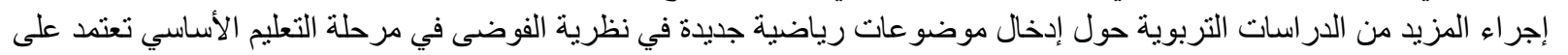

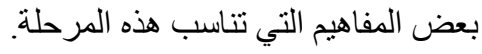

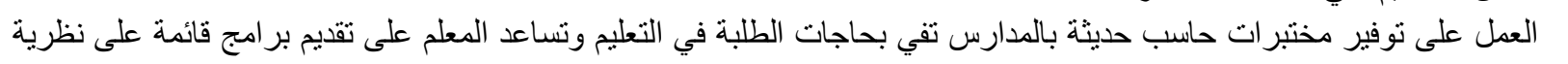
الفوضى مما يسهل تعليمها وتعلمها.

[1] ابو زيد، محمد(2006) : نظرية الفوضى : مقدمة قصيرة، 2006 /7/ 14، الفيزياء التعليمي، نم استرجاعه في: 9 - 9 - 2017م، الساعة

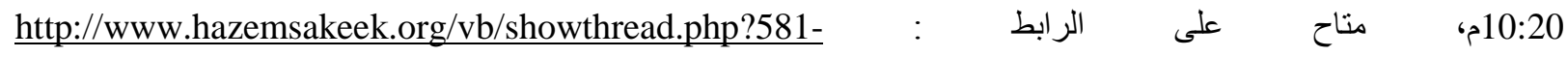
\%D9\%86\%D8\%B8\%D8\%B1\%D9\%8A\%D8\%A9\%D8\%A7\%D9\%84\%D9\%81\%D9\%88\%D8\%B6\%D9\%89\%D9\%85\%D9\%82\%D8\%AF\%D9\%85\%D8\%A9-\%D9\%82\%D8\%B5\%D9\%8A\%D8\%B1\%D8\%A9

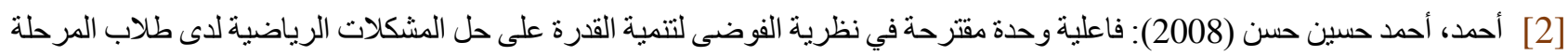

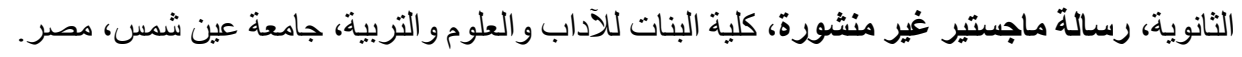

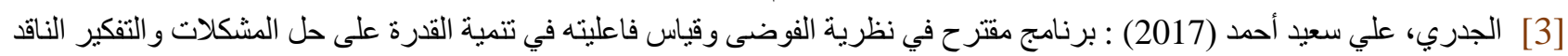

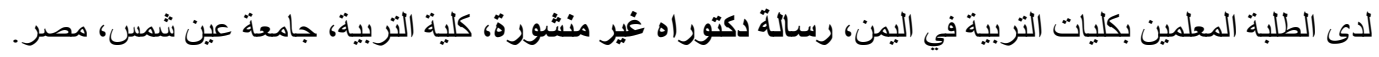


[4] جلايك، جيمس (2000): الهيولية تصنع علما جديدا، المجلس الأعلى لللقافة، المشروع القومي للترجمة، مصر.

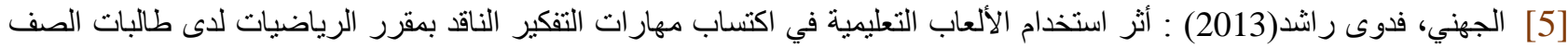

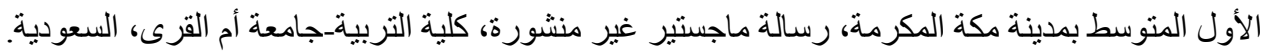

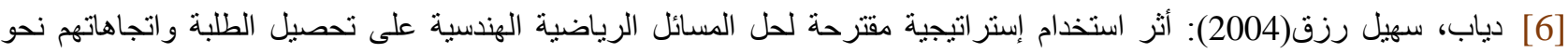

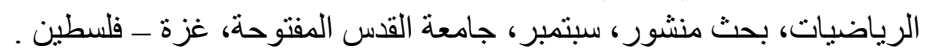

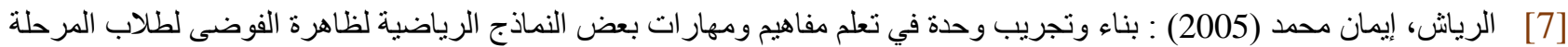

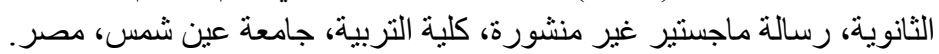

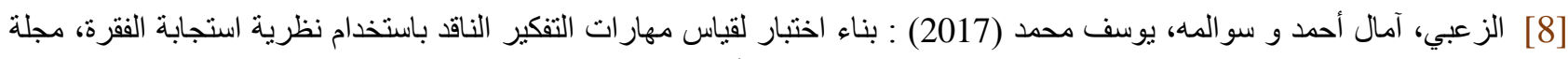

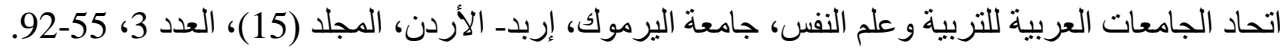

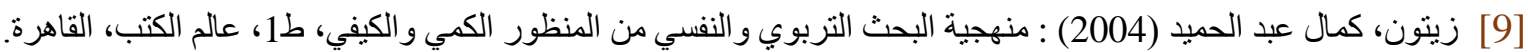

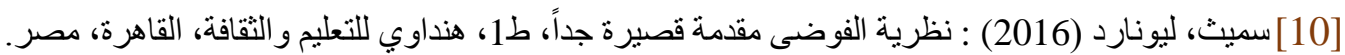

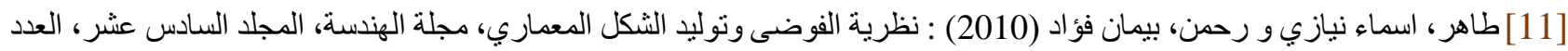
الأول، يناير، 800 .

[12] عبدالمجيد، عبداله ( 2011 ) ) : موقع عبداله عبدالمجيد للعلوم الكونية، 2011 /5 / 23، موقع يهتم بجميع مجالات العلوم الكونية، تم

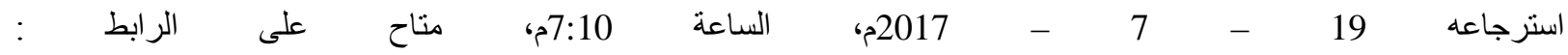
http://kenanaonline.com/users/tetraneutron/posts/265317

[13] العبودي(أ)، شريفة محمد ( 2010 ) : نظرية الفوضى، 2010 / يوليو / 1 موقع الركن الاخضر ، تم استرجاعه 9 - 9 - 2017م، الساعة

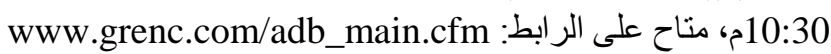

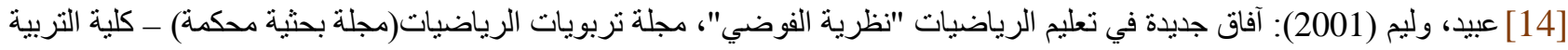

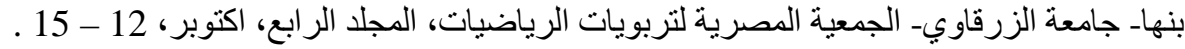

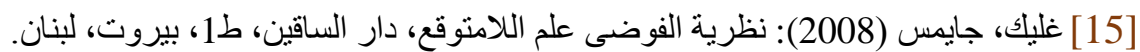

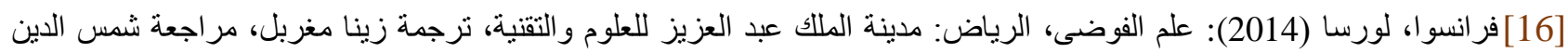

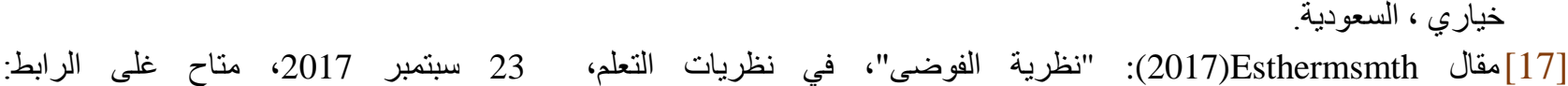
https://www.learning-theories.com/chaos-theory.html

[18] المؤتمر العلمي السنوي (2001): الرياضيات الددرسية معايير ومستويات (توصيات المؤتمر)، الجزء الأول، جمعية تربويات الرياضيات.

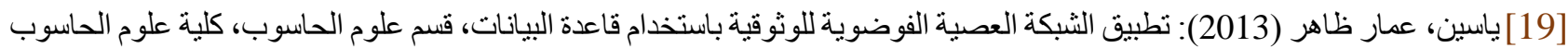

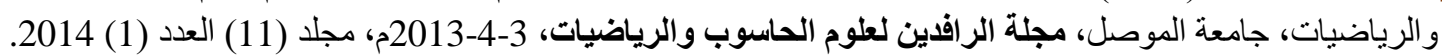

\section{Foreign references}

[20] Garnett P. Williams (1997): Chaos Theory Tamed, Published by arrangement with Taylor \& Francis Ltd, Washington, D.C.// Reprinted (1999), Printed in Great Britain.

[21] Glenn E. James (1996): Chaos Theory, Naval War College, Newport, Rhode Island, center for Naval Warfare Studies, Newport Paper Number Ten, October 1996.

[22] Kellen, Elizabetn(1998): chaos theory and fractal geometry, an internet curriculum master of arts in education (curriculum and instruction) California state university, summer.

[23] Ljupco K, Shiguo L (2010): Chaos - Based Cryptography (Theory, Algorithms and Applications), Library of Congress, Springer-Verlag Berlin Heidelberg.

[24] Richard A. Lesh, Eric Hamilton, James J. Kaput (2007): Foundations for the future in Mathematics Education, Dissertation Abstracts International . Vol (78), no(8), London

[25] Robert, Blizer(2005): Thinking Mathematically Miami Dude College Upper Saddle River, New Jersy Edition.

[26] Steven (2003). "Chaos Theory ". form Wikipedia, the free encyclopedia, Retrieve in 3-9-2017, clock is 4:34m, Affordable from the lacer: https://en.wikipedia.org/wiki/Chaos theory 


\section{RESEARCH ARTICLE}

\section{TEACHING CHAOS THEORY FOR SECONDARY SCHOOL GRADE STUDENTS FROM OF MATHEMATICS TEACHERS' POINT OF VIEW}

\section{Suaad Ali Mohammed AL-Galal ${ }^{1, *}$}

${ }^{1}$ Ministry Of Education, Aden, Yemen.

*Corresponding author: Suaad Ali Mohammed AL-Galal; E-mail: suad18224@gmail.com

Received: 13 July 2020 / Accepted: 19 August 2020 / Published online: 07 October 2020

\section{Abstract}

This study aims to know the importance of teaching chaos theory for secondary school grade students from of mathematics teachers' point of view. The study was limited to a sample of (20) mathematics teachers in Aden Governorate, For the academic year 2019-2020. Where the researcher prepared a proposed unit in Chaos Theory, and she used the descriptive approach. The researcher used the questionnaire as a tool to gather the data and to know the importance and suitable unit for secondary school grade students. To test the indication of differences, a test (Chi-Square Test) $\left(\mathrm{X}^{2}\right)$ is used through the (SPSS) statistics program. The researcher reached the following results: The important of teaching chaos theory for secondary school grade students from mathematics teachers' view. The suitability of the proposed unit in chaos theory for teaching secondary school grade students in terms of (objectives, content, evaluation).

And in the light of that, the researcher made a number of recommendations: The benefit of the proposed unit in Chaos Theory to introduce new mathematical topics in mathematics curricula at the secondary education, and into the teacher preparation programs to help them learn about chaos theory and its applications in life. Introducing topics based on some other chaotic phenomena such as the movement of the heartbeat in the field of medicine, or the movement of the solar system's planets in the field of space, and coding in the field of computers, in the content of mathematics curricula at the secondary education. And Conducting more educational studies on the introduction of new mathematical topics in chaos theory for primary education which depend on some concepts suitable for this stage.

Keywords: Chaos Theory, secondary school, mathematics teachers. 